\title{
Study on the Operating Model of Sports Industry Under COVID-19
}

\author{
Yinze Wang ${ }^{1, *}$ \\ ${ }^{1}$ Rutgers Preparatory School, Somerset, New Jersey \\ ${ }^{*}$ Corresponding author. Email: ywang22@rutgersprep.org
}

\begin{abstract}
On March 11, 2020, the World Health Organization (WHO) officially proclaimed the novel coronavirus (COVID-19) outbreak a global pandemic. Since then, the pandemic has changed various aspects of the world significantly. Being one commonly shared area globally, the sports industry was affected in numerous ways under such an unprecedented situation. This study used the Strengths (S). Weaknesses (W), Opportunities (O), and Threats (T) (SWOT) analysis, aimed at the changes happening within the sports industry after the outbreak of the pandemic compare to the business model of the industry before the pandemic. As a result, the study has found that: first of all, the new operating model embraced by various teams and organizations has created better game experiences for fans, thriving development of sport media, and commonly found adoption of new technology; secondly, the inevitable weakness due to the use of new operating model, including the loss of ticket revenue leading to the diminishing overall revenue, the compromise made by players to agree on pay cut, and the prominence of unemployment; thirdly, future opportunities for the sports industry such as the continued growth of Esports, the chance for the industry to redefine and reevaluate its role within the society, and an increasing viewership in women's sports indicating potential growth within the area in the future; lastly, the threats caused by the outbreak of the pandemic, including the postponement and cancellation of sporting events causing future troubles to athletes and organizations, the mental health issue on athletes because of the ongoing the pandemic, and the long-term health threat towards athletes. In summary, the research of this study contributed to the development of SWOT analysis and broaden the application range of SWOT analysis; it also provides a practical reference and an outlook for the impact of digital technology on the management, operation, and various aspects of online sports events after the pandemic.
\end{abstract}

Keywords: COVID-19, Operating Model, SWOT Analysis, Sports Industry

\section{INTRODUCTION}

In December 2019, a new pneumonia outbreak caused by a novel coronavirus started in Wuhan. Later on, the World Health Organization (WHO) declared on February 11, 2020 that the novel coronavirus would be named as "coronavirus disease-2019 (COVID-19)". With the increasing number of confirmed cases globally, the WHO officially classified the COVID-19 outbreak as a worldwide pandemic on March 11, 2020. Since then, the problem has morphed into global public health and economic crisis that has wreaked havoc on the world's $\$ 90$ trillion economies in ways that haven't been seen in over a century. Sports industry being one important component of the world economy, has played an essential role in its overall growth over the last few years. Without knowing the oncoming pandemic, the projected revenue for the sport industry in 2020 was approximately $\$ 135.3$ billion, and the value of the sports industry was estimated even more at $\$ 756$ billion. However, it turns out that the sports industry has incurred one of the biggest losses in its fairly long history due to the outbreak of the pandemic. The revenue generated within the sports industry was estimated to reach around $\$ 74$ billion, almost half of the original prediction. Teams and organizations are forced to adopt new operating models to help them survive in such unprecedented situations. By doing so, strengths and weaknesses are both being conducted compared to the old model, with potential opportunities and threats in the industry's future.

Eastern and Western scholars have made further studies on the development of the sports industry based on SWOT analysis. This article takes SWOT theory as the basic research theory and summarizes its research 
conclusions. The SWOT analysis method, namely Strength, Weakness, Opportunity, and Threat analysis, was first proposed by Albert Humphrey at the Stanford Research Institute, focusing on the opportunities and challenges faced by specific research topics and potential advantages and disadvantages [1].

According to scholar Chen Zhaonan, when we have a basic understanding of the four elements of SWOT, we should combine our own research topic and environment to conduct a more in-depth analysis to reach the full recognition and understanding application and expansion to more fields. We should give full play to favorable conditions and necessary elements. Mediate adverse elements and potential threats to learn from each component and achieve the best effect [2]. Chinese scholar Jiang Tao et al. proposed that when deciding on a single project, the four elements can be arranged in a matrix form according to certain patterns through research. In this way, the system analysis idea is used to classify and match each factor, and the corresponding series conclusions and countermeasures are drawn [3]. In addition, Tang Taozhi ivided the procedures of SWOT analysis into the following categories: clear target, clear analysis object, information collection and sorting, and conduct SWOT analysis. In SWOT analysis, a SWOT matrix should be constructed first. That is, factors should be sorted according to their levels of importance. Factors with great significance and long-term influence should be ranked in higher orders. Otherwise, factors should be ranked in a secondary way [4]. Meanwhile, Wu Ting believes that SWOT analysis is also rigorous and systematic. It can be done by combining the analysis and diagnosis of the problem with the method used to solve it. Eventually, a more effective solution strategy can be formulated by clarifying the advantages and disadvantages of the research object and analyzing the opportunities and challenges it may face [5]. Yu Xin attributes the advantage of SWOT analysis to its comprehensiveness. It can conduct a more comprehensive, systematic, and accurate analysis of the specific environment under the research object. At the same time, the research results can also help someone make their corresponding long-term development plan [6].

Western scholars have also conducted related studies on SWOT analysis. Michael Porter, an American management expert and scholar from Harvard University proposed four alternative matching schemes based on SWOT analysis in 1985. That is, SO (Strengths Opportunity) strategy, WO (Strengths Opportunity) strategy, ST (Strengths Threats) strategy, and WT (Strengths Threats) strategy. The combination of the four elements can further maximize the advantages of SWOT analysis [7]. Kurttila et al. [8] and Stewart et al. [9] combined the Analytic Hierarchy Process (AHP) with SWOT analysis to reduce the non- objectivity and instability that may exist in SWOT analysis. Dr. Thomas L. Saaty proposed the Analytic Hierarchy Process (AHP) in the 1970s. Its main idea is to form a step model of the main factors involved in the research subject according to the subordinate and associative relations. In this way, the relative importance of each factor can be determined, and the comprehensive judgment and the ranking of importance can be made [10]. At the same time, SWOT analysis can assuredly be categorized into two main factors that exert impact - opportunities and Threats as External Factors and Strengths and Weaknesses as Internal Factors [11]. Lastly, Jia Wang and Zhifeng Wang also suggests that the SWOT analysis can also be applied to distinguish favorable and unfavorable elements under your research topic, tackle existing issues in a predesignated manner, acknowledge the potential problems and challenges, and develop specific plans to solve the correlated problems [12].

To sum up, in the research on SWOT analysis, scholars tend to focus on the research ideas and application methods of SWOT analysis, as well as the collocation of SWOT analysis with other analysis methods. Now, in the context of COVID-19, people's lives have been affected. This can affect the accuracy or availability of SWOT analysis. In the context of COVID-19, this paper takes the sports industry's newly adopted operation and management models as the research topic with SWOT analysis used to focus on the changes and mechanisms of different roles and business models in the sports industry under the COVID-19 pandemic. On the one hand, the conclusion of this paper provides a theoretical basis for the development of SWOT theory and broadens the application environment of SWOT theory. On the other hand, it also provides a practical reference for the influence of digital technology on the management, operation mode, and various aspects of online sports events after the pandemic.

\section{DATA AND METHOD}

\subsection{Data}

This paper selects the sports industry as its research topic, with data sourced from Forbes, New York Times, Statista, Google, etc. All of the data sources were chosen from December 2019 to June 2021 in both primary and secondary data. Data were mainly gathered in the forms of interviews, online source reviews, and financial data analysis. Secondary data was first acquired from various external sources, including teams' and leagues' official websites, online papers, news and articles, books, and analyst reports before the interview. By doing so, the author could come up with specific questions that would help the interviewees. Afterwards, an interview was conducted on seven sports 
fans following different sports leagues and organizations. During the interview, the interviewer made sure to address open-ended questions about their feelings during the pandemic and the platform they use to access the game. Because different interviewees are following other sports leagues and organizations, the all-around and detailed interview was able to be conducted. Interviewees also offered their opinions towards the sports industry under the pandemic, which enriched the perspectives of the paper. The entire interview was recorded and lasted 75 minutes; approximately 80,000 words were transcribed. Online source review and financial data analysis were then further conducted partially based on the interviewees' answers and largely corresponding with the SWOT analysis framework. Together, the interview, online source, and financial data formed the foundation of the paper.

\subsection{Method}

Qualitative analysis was the methodology being used in the paper, and it was particularly ideal for several reasons. Firstly, this research aims to thoroughly examine the changes brought by the new operating model of the sports industry under the pandemic, and there is a significant demand for data richness. Because the sports industry is complex and multi-dimensional, it is better to look at the subject with qualitative analysis rather than a quantitative method. Secondly, academic research on the sports industry under the pandemic is still relatively scarce and in the early stage of development. This study explores the changes being made under the relatively new operating model. The qualitative analysis is particularly well suited to any new or established academic topic that lacks sufficient research.

\section{RESULT AND DISCUSSION}

\subsection{Strength Analysis}

Better game experience for fans. The fan base of each sport within the sports industry is undoubtedly one of the most important factors that contribute remarkably both on and off the court. With the outbreak of the COVID-19 pandemic, sports leagues and organizations have successively announced their safety protocols, including ending in-person fan attendance by any kind. Many people believe that this would result in a disaster for sports fans. However, it turns out that fans now have an unprecedentedly interactive experience with the game. Teams and organizations decided to provide a virtual watching environment with the platform of fans chatting with each other and interacting with the player. In April 2020, the NBA signed a multi-year deal with multiple partners to develop a platform with the help of artificial intelligence and other newest technology to provide a better watching experience according to the increasing need for globalization from the league. The platform offers fans to watch the game in their native languages and presents an online chatting space for fans to publish their thoughts on the game. Besides that, there will also be statistical information, gaming elements, and even historical footage to improve the viewing experience.

The National Football League (NFL) project "Watch Together" is another approach made by sports leagues to improve fans' online viewing experience. This platform enables fans to "Facetime" their friends while watching the live game on Yahoo Sports App. Fans will also be provided with instant replays of key NFL games. All of these allow the fans to watch live streams on their phones or other devices instead of taking the conventional way of watching live games on the TV.

Major League Baseball(MLB) tries to make fans have an actual game experience just like if they were in the stadium. They add features into their official app and offer the fans who are watching the game an opportunity to clap or chant. Then the amount of cheer would be transformed directly into the scoreboard room in the stadium. This way, the operator can transfer the "noise" made at home directly to the amount of virtual noise made at the stadium. There were approximately 90 million interactions like this made last year, which made the MLB decide to keep this feature for the upcoming season.

Sports Media Thriving Under the Pandemic. The outbreak of the COVID-19 pandemic also created a huge opportunity for sports media. With no in-person fan attendance at the game, media become the only channel for people to access the game. Last year in the NBA "bubble", a handful of NBA reporters and writers were selected as the only source to connect the bubble and world outside of it. Media workers had to follow strict safety protocols posed by the NBA, and at the same time, try to present as many stories as possible to the outside world from the bubble. Their hard work was certainly paid off. Since the restart, the NBA social media account has gained more than 3 million new followers while receiving more than 5.3 billion video views.

NBA teams also took the approach of using media sources while in the bubble. With all the players and coaches stayed close together, the Philadelphia 76ers took this chance to experiment with some of their new media features. They were among a few teams that tested the idea of a "virtual media day", where they asked all of the 16 players to create related content about themselves for reporters and writers. The Orlando Magic focused more on using media to stay connected with their fan base. Geoff Krohmer, the director of production and live entertainment at the Magic, set the goal for the team to interact and engage with the fans in 
a unique and brand new way. He acknowledged that the majority of people are spending more time on their phones and the internet because of the pandemic. And because of that, they are more willing to explore new styles and experiments that they have never seen before.

Streaming services was another approach made by sports media that resulted in unexpected success. More and more sports fans are now canceling their pay-TV subscription and set foot into the OTT (stands for overthe-top, delivering service via an internet connection, rather than traditional TV cable) service. According to eMarkrter, the average time spent on OTT service increased by $23 \%$ over the pandemic, including $9.2 \%$ of U.S. consumer claiming that they are considering canceling their TV service. Worldwide sports fans presented a similar trend on this. According to a global study for Synamedia, more than half worldwide sports fans are already picking the side of viewing games on OTT platforms considering that lots of games are no longer provided by TV cables [13].

New Technology boosts the development of the sports industry. In the last decade, technologies and sports have become more and more indivisible counterparts of each other. Modern technologies are playing a crucial role within various aspects of the sports industry. Artificial Intelligence, being one of the major technologies widely used today, has shown its irreplaceable value to boost the development of the sports industry even more. With the pandemic outbreak, artificial intelligence has taken its chance to test and explore even more areas within the sports world.

AI virtual assistant referee is one of the significant experiments being tested during the pandemic. To protect players, sports organizations have posed safety protocols with the idea of isolating players from as many non-players as possible to limit the risk. HawkEye Live is a system that automatically makes all the line calls in tennis, which eliminates the line judges and removes the process for players to challenge the calls made by human referees. Pre-recorded human voice to inform the players of "out", "foot fault" or "fault" is still part of the system to make the players feel like they are still playing the actual game. Stacey Allaster, the U.S.
Open tournament director, expressed that the system particularly suits the ongoing protocols for sports events since every tournament area has been requested to limit the necessary number of people who need to be in contact with the players. Using AI technology like Hawk-Eye Live, the number of judges on court can be reduced from roughly 350 to under 100. Players favored the system as well. Donald Young, a player who played in a game using Hawk-Eye Live, thought the system is particularly useful under Covid-19. He also acknowledged that the system is better at making calls than multiple human eyes add together.

Artificial Intelligence was also being used to analyze behaviors during the pandemic, which functions to help teams and organizations predict the area with potential revenue. With AI's help, data is being generated more quickly and directly. Data can further assist the organization in making decisions on where they should make their investment. More specifically, they can improve marketing efficiency by providing concrete targets based on fan demographics, which consist of personal interests, media purchasing behaviors, shopping habits, and so on. Companies like the Nielsen Corporation recognized this trend and have already acquired AI tools that help them predict consumer behaviors, especially on sports brands. By doing so, they will be able to make better decisions on media rights investment and related sponsorship8. With the ongoing pandemic that inhibits teams and organizations from making revenue from traditional areas like ticket revenue and related retail and sporting services, the adoption of AI technology certainly lighted the path for the sports industry to look in another direction.

\subsection{Weakness Analysis}

The loss of ticketing revenue leading to the overall loss of revenue. Sports Industry was considered one of the fastest-growing industries in the world. Without knowing the upcoming pandemic, the projected revenue and value for sport industry in the year of 2020 was estimated to reach the highest in its history. See Figure 1. 


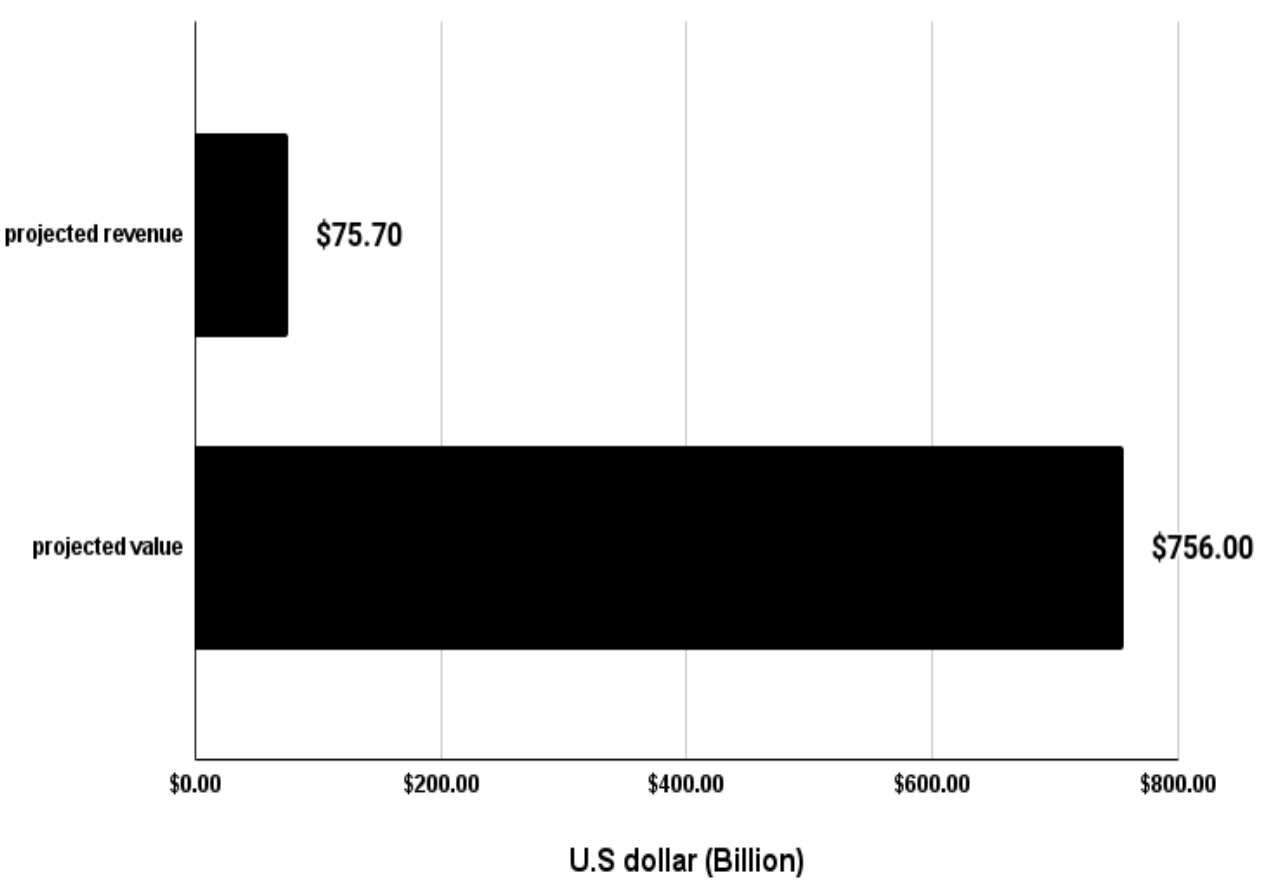

Figure 1. Sports industry Projected Revenue and Projected Value in the Year of 2020

Data source: https://www.statista.com/statistics/269797/worldwide-revenue-from-sports-merchandising/

Everything was growing fast in the sports world until the arrival of the pandemic. The pandemic outbreak hit hard on the four major North American sports leagues and the NCAA March Madness. The revenue-making ability of these organizations has been tested by the ongoing pandemic significantly. See Figure 2 .

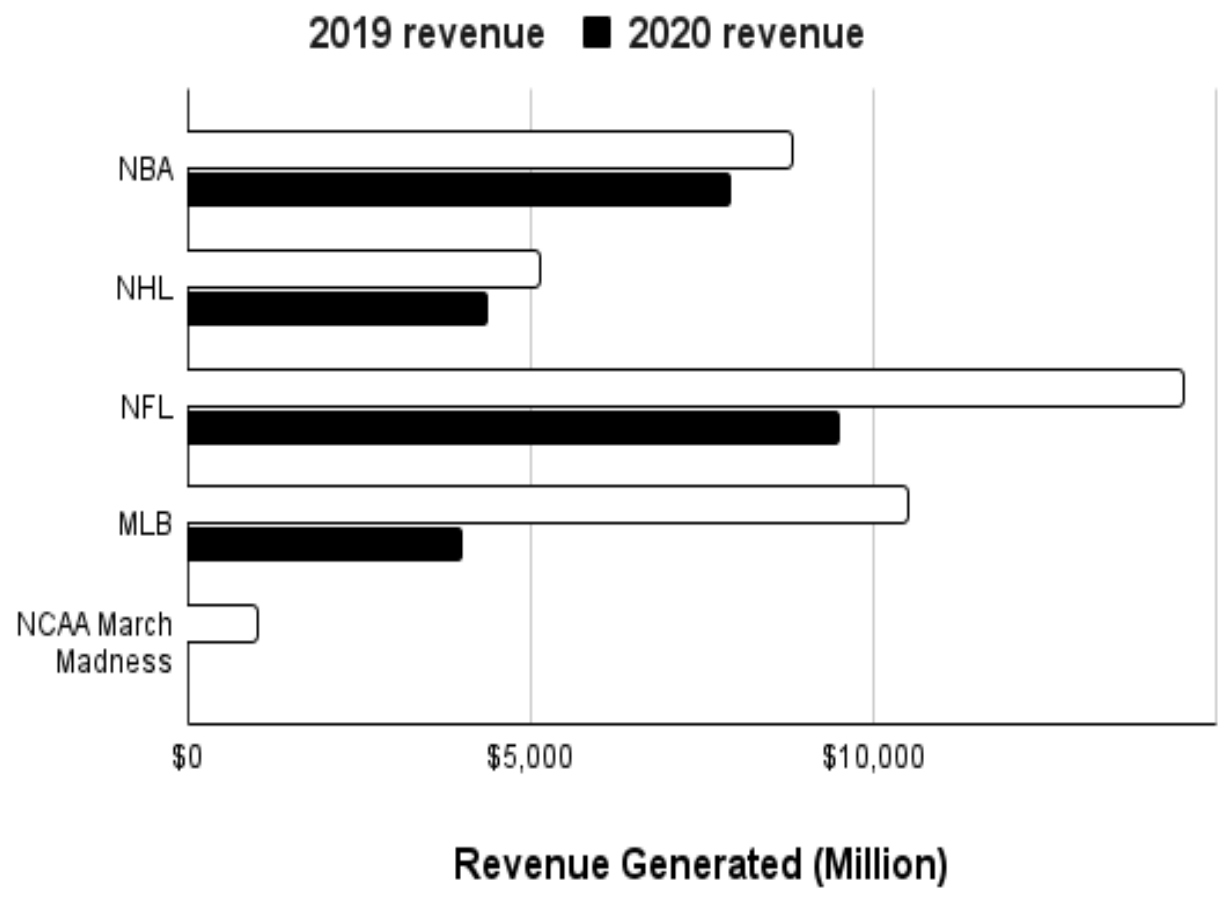

Figure 2. Revenue Generated by the Four Major Leagues and NCAA March Madness in the Year of 2019 and 2020

Data source: https://www.forbes.com/sites/justinbirnbaum/2021/03/06/major-sports-leagues-lost-jaw-droppingamount-of-money-in-2020/?sh=3cee1a9169c2 
The elimination of in-person fan attendance to sporting events played one of the biggest roles in the overall loss of revenue. With zero in-person attendance to the game due to safety reasons, ticketing revenue was eliminated during the pandemic. The three major sports organizations in the United States, the MLB (Major League Baseball), NBA, and NHL (National Hockey League), might lose up to $\$ 7.9$ billion in ticket sales due to the pandemic, according to data from SafeBettingSites. Among these leagues, the MLB was estimated to incur the biggest loss regarding ticketing revenue. According to data presented by TicketIQ, the professional baseball league in the United States could lose up to $\$ 5.1$ billion in ticket revenue as a result of the COVID-19 outbreak. In the area of basketball, the potential loss of ticketing revenue for the NBA was estimated to reach $\$ 1.7$ billion this season even with the restart of the game in the "bubble", according to the TicketIQ data. The Los Angeles Lakers was the team that lost the most in the area of ticketing revenue. As of March 2020, the team has already lost $\$ 82.1$ million in ticketing revenue, which almost doubled the amount lost by the New York Knicks, who lost $\$ 46.1$ million in the same area [14].

Pay cuts agreed by athletes. With the outbreak of the pandemic, jobs within the sports industry were facing unprecedented risk globally. Athletes have to go through the inevitable process of finding a safe environment to reschedule their practice. Some of the athletes commonly find themselves using their home as a training area to stay fit for the unpredictable restart of their season. Pay cuts were also commonly found among athletes, especially those star players who are considered some of the wealthiest people in the world. Lionel Messi, one of the best players ever played the soccer game, decided to cut $70 \%$ of his salary to help his club FC Barcelona pay countless non-playing members on the team so they can stay in the organization and have the money to provide for their families. Messi, in his statement, announces that he and the entire FC Barcelona team will keep on making contributions like this under such a particular situation. NBA players have also agreed on a $25 \%$ pay cut starting on May 15 2020. In total, there will be a $\$ 30$ million cut on player's salaries. Players are receiving less money, but it was the move that had to be made under such an uncommon situation for the future of the sports industry.

Unemployment is becoming prominent. Individuals working in sports-related retail and sporting service have arguably incurred an even bigger loss. Wisconsin, a state with various sports teams competing in numerous sports leagues and organizations, had to cancel all of its sporting events due to the pandemic. This action taken by the state eventually resulted in a total of 46 million revenue loss, according to New York Times, and the outcome of people forced to leave their workplace. As the COVID-19 cases kept rising since it first hit Wisconsin, 184 employees and vendors working at the Lambeau Field (the home field for the Green Bay Packers) had to leave their workplace with no signs of a specific returning date. Over 100 miles south of Green Bay, Milwaukee lost an estimated 6838 employees working in sport-related enterprises. Based on Emsi estimation, the model shows that more than 5000 additional jobs were lost throughout the state of Wisconsin and the initial loss of 2200 employment due to safety measures of closing stadiums in Green Bay and Milwaukee. Nation-wise, over $1 / 3$ of the people previously working for sports-related jobs became unemployed. As of October, 111000 people were jobless [15].

\subsection{Opportunity Analysis}

Esports industry thriving under the pandemic situation. The pandemic outbreak has boosted the incentive from teams and organizations to pursue new platforms for better fan engagement, which can lead to more revenue being generated. Esports is one of the most successful sports industries that, in a way, grew even stronger under the pandemic situation. They formed an even closer connection with fans, professional athletes, and in general, the sports world.

With people worldwide forced to spend the majority of their time at home due to the pandemic, esports have gained more viewership and engagement number, as well as a new audience base. According to Newzoo, in 2020, esports attracted 485 million viewers, representing an $11 \%$ increase from 2019. The revenue generated by the esports industry reached $\$ 1.1$ billion, which increased $15.7 \%$ compared to 2019 [16].

NBA 2K esports league was one of the most successful esports platforms during the pandemic. As for now, 22 out of the $30 \mathrm{NBA}$ teams already built up their own NBA $2 \mathrm{~K}$ esports teams. They competed in season 3 of the NBA $2 \mathrm{~K}$ league during the pandemic. As a result, the average unique viewers per stream of the $2 \mathrm{~K}$ league on Twitter increased by $69 \%$ compared to the previous year. The average minute audience per stream increased by $48 \%$, while the average minute watched each stream increased by $55 \%$.

A much closer relationship between professional athletes and esports were also formed during the pandemic. With their games being postponed or canceled, pro athletes can now spend more time on some of their leisure activities, including esports. Video game company Take-Two-Interactive with its $2 \mathrm{~K}$ studio, took the opportunity to cooperate with the NBA Player Association to host an NBA 2K20 competition played by 16 NBA players, with the likes of Kevin Durant and Trae Young. The games were broadcasted on ESPN with the hope of attracting even more viewership. It was a win-win situation for both pro 
athletes and the esports industry, with players finding a new platform to reach their fans. The esports industry uses athlete's star power to keep on increasing their influence within the sports world.

Redefine and reevaluate the relationship between sports and society. After all, the sports industry is part of society, which means that what has been happening within society will inevitably influence the role of the sports industry. With so much societal unrest happening in the last year, sports teams and organizations face a great opportunity to redefine their roles within society and reevaluate the actions they should be taking corresponding to some of the new values embraced by players and fans.

According to Deloitte's Global Millennial Survey, a proactive reaction to social justice is especially crucial to younger generations, more values-driven in their interactions with brands and enterprises. Sports leagues and organizations are aware of this phenomenon. As a result, teams and athletes are becoming more and more important influencers to promote positive changes to society. In August 2020, the Cleveland Browns, Cavaliers, and Indians launched three-team cooperation to raise awareness about social justice concerns. NBA star player Jrue Holiday and his wife Lauren, a former soccer player for the U.S. women's national team, have built a social justice fund with their remaining game checks, valued up to $\$ 5.3$ billion. NBA superstar LeBron James formed a voting rights organization called More Than a Vote, which encourages AfricaAmerican to utilize their right and register to vote while simultaneously combating voter suppression. Many players also joined the BLM protest. NBA players Jaylen Brown and Malcom Brogdon participated in the protest in Atlanta. Brogdon also spoke to the crowd during a demonstration. Sports leagues showed their support to the BLM and inequality by donating. The NBA formed its non-profit foundation. Each NBA 20 teams will donate $\$ 1$ million annually for the following ten years, totaling $\$ 300$ million. The NFL also donated $\$ 250$ million over the next 10 years to fight for systemic racism.

Rising level of interest in women's sport based on increasing amount of viewership. Women's sport was another area experiencing changes over the pandemic. The rising level of investment to women's sports also foreshadows the industry's bright future with more opportunities being provided.

While the NFL, NHL, NBA, and MLB all had double-digit drops in viewership in 2020, the National Women's Soccer League (NWSL) and the Women's National Basketball Association (WNBA) both experienced viewership changes in the opposite way. Being the first sports league to return from the COVID19 shutdown in North America, The NWSL is gaining a $493 \%$ increasing in viewership and a $152 \%$ increasing in social media mentions. In 2020, the championship match-up drew 653,000 viewership on CBS, one of the seven most-watched NWSL games ever [17]. In 2020, the WNBA's regular-season viewership also increased by $68 \%$, with the season's restart in the "bubble".

\subsection{Threats Analysis}

The Postponed or Cancelled Sporting Events causing troubles towards athletes and organizations. The postponement or cancellation of sporting events was another decision made by various leagues and organizations due to the pandemic. The result of this action turns out disastrous for the sports world.

The NCAA March Madness tournament was officially canceled on March 12, 2020 due to the pandemic. This announcement meant that their college basketball career has come to a close in one of the most devastating ways for many players. Since 1939, the NCAA men's basketball tournament has been held every year. Many players were in shock after hearing the news. University of Dayton senior Trey Landers, being part of the team that was number one seed in the Atlantic 10 conference, expressed that he wished that the cancellation was just a dream to play another game with his teammates. Indiana University forward Tracey Jackson-Davis said that he felt sorry for the seniors on their team who worked extremely hard throughout the year. NCAA women's basketball tournament was being canceled on the same day. University of Oregon guard Minyon Moore stated that her college career is over makes her feel broken inside. Minyon's coach Kelly Graves posted that it is disappointing to realize that the team still has "unfinished business". The NCAA organization also experienced a loss because of the cancelation. The diminished revenue generated by the NCAA resulted in the financial payment to Division 1 universities at the end of the 2019-2020 academic year would only be $\$ 225$ million----- $37.5 \%$ of the planned $\$ 600$ million.

The Postponement of the 2020 Tokyo Olympic and Paralympic games was another major hit for the sports world. According to sports economics expert professor emeritus Katsuhiro Miyamoto of Kansai University, the postponement of the Olympics for one year can result in $¥ 640.8$ economic loss, and the cancellation of the Olympics can lead up to $¥ 4.5$ trillion economic loss. The astronomical figure of the postponement cost is partially caused by the additional cost of $¥ 22.5$ billion on extra maintenance for the Olympic village and the venues, and another $¥ 390$ billion used on specific groups to stay in place for another year [18]. The postponement of the Olympic also tested athlete's adaptability to changes. For Tyrone Pillay, a South African Paralympic shot putter, the postponement of the Paralympic was not the best of news for him. Tyrone was planning to retire after the Paralympic, and he felt that his form was at its best 
before the Paralympic. He has been throwing the best distance and staying in the best shape both mentally and physically. The postponement changed everything for him. He had to make new training plans without attending competitions until the Paralympic. According to him, the mindset also needed to be adjusted, which has been another challenge for all the athletes planning on attending the Olympic and Paralympic.

The COVID-19 pandemic affecting athlete's mental health. For many people, including athletes, life under the pandemic was a stressful one. With social justice issues and greater working pressure because of the particular working environment, mental health is becoming even more serious. Many professional athletes have openly reported and discussed their mental health struggles as well. In the period between midMarch and August in 2020, 22.5\% of elite athletes reported feeling down or depressed on more than half of the days of the week, while COVID-19 limitations on sports training were in place, according to a survey released by Stanford University and Strava. The survey also indicates that only $3.9 \%$ of athletes reported similar difficulties earlier in 2020, before the pandemic struck their world, and the overall athletes are reporting mental health issues accumulated a $447 \%$ increase. Researchers also discovered that endurance athletes such as cyclists and runners were $5.9 \%$ more likely than the general population to report feeling apprehensive for more than half of the week during the pandemic than before [19]

NBA star Kevin Love was worrying about the impact of COVID-19 on player's and everybody else's mental wellness as someone who personally struggled from it before. He is concerned because he understands what can happen when individuals lose a loved one, become obsessed by loneliness and isolation, face job uncertainty and financial hardship, and internalize their stress rather than seek help from a health professional. Legendary swimmer Michael Phelps says that he has read "too many articles" related to suicide amid the pandemic. It destroys him every time he sees it as someone who has also openly talked about his fight against depression and suicidal thoughts thought. San Antonio Spurs guard DeMar DeRozan, who has been fighting with mental health issue, took a different approach by hosting an Instagram live conversation about mental health awareness to help others who might be struggling from it.

The COVID-19 virus causing long-term health threats to players. Although athletes competing at the top levels are often young and in excellent physical condition, they are still human beings, which means that diagnosing with the virus is still within their reach. Research has shown that the virus can cause long-term health problems, including damage lungs, brain, kidneys, and heart.
The Boston Red Sox's pitcher, Eduardo Rodriguez, was diagnosed with COVID-19 on July 7 2020. Even though he was able to return 11 days after, the MRI still revealed myocarditis (heart inflammation) on him, a potentially fatal side effect of the virus. According to the Centers for Disease Control and Prevention (CDC), people with a body mass index (BMI) of more than 30 are particularly vulnerable to the virus. This statement has put more than 300 NFL players who weigh 300 pounds or more into a bad position. Although the League has not released any information on the infection rate, the players' union reported 95 positive tests in July 2020.

Some athletes have also openly discussed their struggles with the long-term effect of diagnosing with the virus. Orlando Magic center, Mohammed Bamba, was diagnosed with the virus on June 11 2020, causing him to play only 10 minutes in the $2019-2020$ season even after he was tested negative. In the 2020-2021 season, Bamba has only appeared in 16 out of 36 games before the All-Star break. Bamba has dealt with a loss of taste and smell, and fatigue, and muscle stiffness, which largely affected him as a basketball player. The virus has also affected many players' overall season performance. Chicago White Sox 25-year-old third baseman, Yoán Moncada, was diagnosed with the virus before the start of the 2020 season. Moncada had an outstanding season in 2019. He finished with a .315 batting average and 25 homeruns. After he was diagnosed with the virus, his numbers in the 2020 season plummeted. He finished with a .225 batting average and only 6 homeruns. In one interview, he openly stated that the COVID-19 virus has made him feel different in many ways. He felt a lack of strength and energy, which made a large impact on his performance.

\section{CONCLUSION}

In conclusion, the new operating model has shown distinctive strengths and weaknesses, with potential opportunities and threats of the sports industry lie in the future. First, the pandemic outbreak has encouraged the sports industry to adopt a new operating model to put more investment on various online platforms. As a result, certain strengths be seen compared to the conventional platform. A better game experience is provided to the global fan base; sports media is one of the fields that has unexpectedly experienced major growth during the pandemic; technology has become an even more important counterpart to the development of the sports industry. For various sports leagues and organizations, the adoption of the new operating model has proved to be a wise and crucial decision that not only helped them to keep their already existing fan base or even attracting new followers but also provided them a new way of operating their business within the sports 
industry in the future. The new operating model under the pandemic also inevitably contains weaknesses. To name a few, the loss of ticket revenue has become a significant problem within the sports industry which plays a big part in the overall loss of revenue; athletes are also forced to make compromises, including pay cuts due to the fact that teams and organizations are not as profitable as before; unemployment issue has also become prominent under the pandemic with numerous retailers and people working for sports service lose their jobs due to the prohibition of in-person fan attendance. Every sword is double-edged, even though online investment within the sports industry has benefited many parties, the inevitable abandonment of the old, traditional operating model caused losses to many conventional profit-making fields within the sports industry. Athletes, teams, and organizations are all losing income in their own and distinctive ways. To make the situation even worse, unemployment became another major problem that had to be dealt with by various parties within the industry. Some opportunities can also be found based on some of the trends happening during the pandemic. Esports industry has particularly enjoyed its time during the pandemic; social events that happened during the pandemic forced the sports industry to redefine and reevaluate its role within the society and take even bigger social responsibility in the future; women's sports have experienced an increasing amount of viewership which indicate the great opportunity for the growth of women's sports industry in the future. Underlying threats also lie in the future of the sports industry. The postponement and cancellation of certain sporting events have proved or predicted to be troublesome for athletes and organizations; with the rising level of mental health issue found among athletes, the outbreak of the pandemic has proved to make it even worse; long-term health issue are also affecting performance or even the career of players diagnosed with the virus.

It is recommended that different parties within the sports industry be aware of the strengths, weaknesses, opportunities, and threats caused by the new operating model under the pandemic. Teams, leagues, and organizations that benefit from the model's strength should fully take advantage of it and try to maximize its strength even after the pandemic. The NBA, NFL, and MLB should keep their existing online interaction platform and keep developing it in the future. Various parties should also consider applying technologies into their businesses, which help themselves in numerous ways and contribute to the overall development of the sports industry. Parties that incurred losses under the pandemic or experienced the weakness part of the new operating model should work on minimizing their losses at the point and explore better ways that would help them survive or new platforms that would generate revenues. Teams and organizations that incurred a huge ticket revenue loss should start investing in online platforms that still flourished under the pandemic. People who lost their jobs can also transfer their retailing or sport service online or create a partnership with their local teams. Fields that see opportunities under such unprecedented time should keep exploring the real meaning of its opportunity and, most importantly, take the opportunity eventually, giving them a leading position when the pandemic is over. Social justice issue is becoming increasingly important under such unprecedented times. It would be ideal and appropriate for athletes, teams, and organizations to add more elements to their brand to advocate their values on related social issues. It might be a good time for them to look beyond the sports industry and build an even closer connection with society. Sporting events threatened by the pandemic should also try to minimize losses by hosting zero in-person fan attendance games or working for online platforms to present the games completely online. It might be necessary to postpone the events, but it is definitely unnecessary to cancel the game entirely. Athletes facing mental or physical health issues should always put their personal health in the first place. Athletes who have overcome their mental health issues can share their stories to help those in need.

The research result of this paper, on the one hand, provides a theoretical basis for the development of SWOT theory. Within the paper, the SWOT method has shown its distinctive characteristic of providing a thorough analysis. The specific strengths and weaknesses of the new operating model under the pandemic and the opportunities and threats indicated based on the ongoing trend during the pandemic are shown separately. Together, they formed a picture of the current situation of the entire sports industry under the pandemic and the potential future of the industry when the pandemic is over. Sports leagues and organizations can use the research conclusion as a reference for them to evaluate the areas they should be further working on and the field they should offer special attention. On the other hand, the paper provides a practical reference for the influence of digital technology on the management, operation mode, and various aspects of online sports events after the pandemic. The ongoing trend of increasing online investment under the new operating model can be seen as part of the larger trend in the digital age. With technologies now entering people's lives daily, the new operating model has a great chance of taking over the conventional model even after the end of the pandemic. In the context of this, the research conclusions of the paper can be seen as a prediction of the operating model of the sports industry when the pandemic comes to an end.

\section{REFERENCES}

[1] Nyarku, K., \& Agyapong, G. (2011). Rediscovering 
SWOT analysis: The extended version. Academic Leadership: The Online Journal, 9(2), 28.

[2]Zhaonan Chen, A Brief Introduction to SWOT Analysis [J]. Information Theory and Practice, 1995, 03:13-13.

[3] Jiang Tao, Jiang Mei. Brief Discussion on the Application of SWOT Method in the Analysis of Urban Planning Strategy in China [J]. Modern Urban Research, 2005, 000(012):51-55. [3] C. Baier, J-P. Katoen, Principles of Model Checking, MIT Press, 2008.

[4] Tang Taozhi. SWOT Analysis and Competitive Strategy Selection of Competitive Intelligence [J]. Journal of Intelligence, 2002(03):36-37.

[5] Wu Ting. Research on Overseas Education Strategy of Higher Vocational Colleges based on SWOT Analysis [J]. Education and Careers, 2020(20). DOI:10.13615/j.cnki.10043985.2020.20.008.

[6] Yu Xin. The Discussion of Management Review in OMCL Through SWOT Analyisis [J]. Chinese Journal of Pharmaceutical Science, 2020, V. 55(19):89-93. DOI: 10.11669/cpj.2020.19.016.

[7] Yang Mingxiang. Zone and Port Linkage: Towards Free Trade Zone [J]. Ningbo Economy: Financial and economic Perspective, 2005(12):21-23.

[8] Kurttila, M., Pesonen, M., Kangas, J., \& Kajanus, M. (2000). Utilizing the analytic hierarchy process (AHP) in SWOT analysis-a hybrid method and its application to a forest-certification case. Forest policy and economics, 1(1), 41-52. DOI: $\quad$ https://doi.org/10.1016/S13899341(99)00004-0.

[9] Stewart, R. A., Mohamed, S., \& Daet, R. (2002). Strategic implementation of IT/IS projects in construction: a case study. Automation in construction, 11(6), 681-694. DOI: https://doi.org/10.1016/S0926-5805(02)00009-2.

[10] Saaty T.L. (1988) What is the Analytic Hierarchy Process?. In: Mitra G., Greenberg H.J., Lootsma F.A., Rijkaert M.J., Zimmermann H.J. (eds) Mathematical Models for Decision Support. NATO ASI Series (Series F: Computer and Systems Sciences), vol 48. Springer, Berlin, Heidelberg. DOI; https://doi.org/10.1007/978-3-642-83555$1 \_5$.

[11]Consorti, F., Kanter, S. L., Basili, S., \& Ho, M. J. (2021). A SWOT analysis of Italian medical curricular adaptations to the COVID-19 pandemic: a nationwide survey of medical school leaders.
Medical Teacher, 1-

8., DOI: 10.1080/0142159X.2021.1877266.

[12]Wang, J.; Wang, Z. Strengths, Weaknesses, Opportunities and Threats (SWOT) Analysis of China's Prevention and Control Strategy for the COVID-19 Epidemic. Int. J. Environ. Res. Public Health 2020, 17,2235. https://doi.org/10.3390/ijerph17072235.

[13]https://www.sportsbusinessjournal.com/SBBlogs/COVID19-OpEds/2020/07/20.

[14]https://www.safebettingsites.com/2020/08/19/threemajor-us-sports-leagues-to-lose-7-9bn-in-ticketrevenue-amid-covid-19-outbreak/.

[15]https://www.nytimes.com/interactive/2020/12/13/sp orts/coronavirus-sports-economy-wisconsin.html

[16]https://www.yahoo.com/entertainment/nba-2kesports-league-grows-153056772.html.

[17]https://www.adweek.com/convergent-tv/how-thepandemic-super-charged-broadcasts-interest-inwomens-sports/.

[18]https://www.japantimes.co.jp/news/2020/04/04/nati onal/politics-diplomacy/2020-tokyo-olympicspostponement/\#: :text=On\%20March $\% 2019 \% 2 \mathrm{C}$ $\% 20$ he $\% 20$ concluded,cost $\% 20$ about $\% 20 \%$ C2\%A5 4.5\%20trillion.\&text $=$ And $\% 20$ post $\% 2$ DOlympics $\% 20$ effects $\% 20$ would,a $\% 20$ result $\% 20$ of $\% 20 a \% 20$ delay.

[19]https://time.com/5901424/covid-sports-mentalhealth/. 